\title{
THE ROLE OF RESOURCES IN RECOMBINATIONS AND THE DEGREE OF NOVELTY OF PRODUCTS
}

\author{
O PAPEL DOS RECURSOS NAS RECOMBINAÇÕES E O GRAU DE NOVIDADE DOS PRODUTOS
}

EL ROL DE LOS RECURSOS EN LAS RECOMBINACIONES Y EL GRADO DE NOVEDAD DE PRODUCTOS

Juan Pablo Camani ${ }^{1}$

Cite as - American Psychological Association (APA)

Camani, J. P. (2021, Sept./Dec.). The role of resources in recombinations and the degree of novelty of products. International Journal of Innovation - IJI, São Paulo, 9(3), 522-556. https://doi.org/10.5585/iji.v9i3.19958.

\begin{abstract}
Objective of the study: To explain the characteristics and dynamics of resources and recombinations associated with developing products with low and high novelty.

Methodology/Approach: The method was an integrative review of the literature on recombinant innovation. It included a creative synthesis that resulted in a theoretical model.

Originality/Relevance: The research addresses topics the literature neglects, like explaining which resources and recombinations and why could relate to high or low product novelty.

Main results: Certain features of resources (i.e., heterogeneity, specificity, accessibility) with high and low levels may differently influence costs, variety, and frequency of recombinations and, in turn, product novelty. To develop highly novel products, tangible resources, and internally produced new resources may be essential, as knowledge by itself may not be sufficient.

Theoretical contributions: Different resource characteristics and their influence on recombinations may help explain whether a product will have low or high novelty. By going beyond the novel recombinations, the research expands the literature's understanding of recombinations and product novelty.

Managerial contributions: Companies could assess ex ante which degree of product novelty besides types and costs of recombinations would result from their pools of resources. This assessment would make innovation more efficient for companies with fewer resources, like may occur in emerging markets.
\end{abstract}

Keywords: Resources. Innovation. Products. Degree of novelty. Recombinations.

\section{Resumo}

Objetivo do estudo: Explicar as características e dinâmicas dos recursos e recombinações associadas ao desenvolvimento de produtos com baixa e alta novidade.

Metodologia/abordagem: Foi realizada uma revisão integrativa da literatura sobre inovação recombinante. Incluiu uma síntese criativa para desenvolver um modelo teórico.

Originalidade/Relevância: A pesquisa aborda tópicos que a literatura negligencia, como explicar quais recursos e recombinações e por que poderiam estar relacionados à alta ou baixa novidade do produto.

Principais resultados: Certas características de recursos (heterogeneidade, especificidade,

\footnotetext{
${ }^{1}$ Dr. in Business Administration, Universidad Nacional de Río Negro. Escuela de Economía, Administración, y Turismo. Río Negro, Argentina. jpcamani@unrn.edu.ar
} 
acessibilidade) em níveis altos e baixos influenciariam diferentemente os custos, a variedade e a frequência das recombinações e, por sua vez, a novidade do produto. Além disso, no desenvolvimento de alta novidade, recursos tangíveis e novos recursos (produzidos internamente) podem ser essenciais, pois o conhecimento por si só não seria suficiente.

Contribuições teóricas: Diferentes características de recursos e sua influência nas recombinações podem ajudar a explicar se um produto terá uma novidade baixa ou alta. Ao ir além das novas recombinações, a pesquisa expande a compreensão da literatura sobre recombinações e novidade do produto.

Contribuições gerenciais: As empresas poderiam avaliar ex ante que grau de novidade e que tipo e custos de recombinações resultariam de seus recursos. Esta avaliação tornaria a inovação mais eficiente para empresas com menos recursos, como pode ocorrer em mercados emergentes.

Palavras-chave: Recursos. Inovação. Produtos. Grau de novidade. Recombinações.

\section{Resumen}

Objetivo del estudio: explicar las características y la dinámica de los recursos y las recombinaciones asociadas con desarrollar productos de baja y alta novedad.

Metodología/ enfoque: se realizó una revisión integradora de la literatura en innovación recombinante. Incluyó una síntesis creativa para desarrollar un modelo teórico.

Originalidad/ Relevancia: la investigación aborda temas que la literatura descuida, como especificar qué recursos y recombinaciones y por qué podrían relacionarse con una alta o baja novedad de productos.

Resultados principales: ciertas características de los recursos (heterogeneidad, especificidad, accesibilidad) con niveles altos y bajos influirían diferentemente sobre los costos, la variedad y frecuencia de las recombinaciones y, a su vez, la novedad del producto. Además, al desarrollar alta novedad, los recursos tangibles y los recursos nuevos (producidos internamente) podrían ser esenciales, porque el conocimiento por sí solo no sería suficiente.

Contribuciones teóricas: las diversas características de los recursos y su influencia en las recombinaciones podrían contribuir a explicar si un producto tendrá poca o mucha novedad. $\mathrm{Al}$ ir más allá de las recombinaciones novedosas, la investigación amplía la visión de la literatura sobre recombinaciones y grado de novedad.

Contribuciones gerenciales: las empresas podrían evaluar ex ante qué grado de novedad, tipo y costos de recombinaciones resultarían de sus recursos. Esta evaluación eficientizaría la innovación en las empresas con menos recursos, como puede ocurrir en los mercados emergentes.

Palabras clave: Recursos. Innovación. Productos. Grado de novedad. Recombinaciones.

\section{Introduction}

Resources can be essential for innovation. When used, they provide services that integrate through different recombinations (Kalthaus, 2020). The outcome of this integration is the creation of knowledge that supports new products design. This knowledge may vary in novelty (Popadiuk \& Choo, 2006). Thus, the resulting new products can vary their degrees of novelty (DN) too. The $\mathrm{DN}$ is a product's innovativeness level for an industry and a firm (Garcia \& Calantone, 2002; Si \& Chen, 2020). It varies between low or incremental and high or radical (Forés \& Camisón, 2016).

Though the different concepts that lead to DN are clear, uncertainty complicates resource use by practitioners. They do not know ex ante which specific recombinations will 
create a specific DN (Mukherjee, Uzzi, Jones \& Stringer, 2016). In emerging markets, risking scant resources is a relevant obstacle for innovation (Silva, Braga \& Rebouças, 2016). Thus, low DN is widespread among small and medium-sized enterprises (de Carvalho, da Silva, de Carvalho, Cavalcante \& Cruz, 2017). In developed markets, attempts to reduce uncertainty have also led to low and middle DN recombinations ruling for the last 150 years (Buchanan, 2015; Youn, Strumsky, Bettencourt \& Lobo, 2015). The problem is not only that low DN wastes innovation potential to increase competitiveness (Alvarenga, 2016); also, it remains unclear how resources and recombinations may influence a specific DN.

On the theoretical side, the body of literature on recombinations generally does not specify the DN recombinations accomplish (Savino, Messeni Petruzzelli \& Albino, 2015). The focus is on novel recombinations of existing resources (Arthur, 2009) and understanding organizational combination capabilities (Belenzon, 2012; Kogut \& Zander, 1992). Novel resources come from outside the industry through absorptive capacity (Ahuja, Lampert \& Tandon. 2008; Forés \& Camisón, 2016).

The available literature on the topic acknowledges that recombined resources can be intangible and tangible (Nelson \& Winter, 1982; Schumpeter, 1939). However, according to the literature, resources mean knowledge: Recombinations' main output and input (Kang, Baek \& Lee, 2019; Teece, Peteraf \& Leih, 2016). Thus, the literature downplays the role of non-knowledge-based or tangible resources in recombinations (Arts \& Veugelers, 2015; Lengnick-Hall \& Griffith, 2011). The view on them is homogenous and generic, molded by knowledge through novel combinations, but it is not the other way around.

Still, tangible resources can be physically and subjectively heterogeneous (Foss \& Klein, 2012); hence, they might not be always malleable for novel combinations. Heterogeneity suggests that interactions with the same knowledge-based resource should be different. Thus, tangible resources could facilitate or not certain combinations with knowledge, leading to different outputs (Popadiuk \& Choo, 2006). Since resources, recombinations, and new knowledge could vary, the complexity of recombinations and uncertainty may increase (Arthur \& Polak, 2006).

According to Savino et al. (2015), the recombinant innovation literature still does not understand recombination dynamics well. We argue one reason might be the lack of theorizing about tangible resources and their interaction with knowledge. As it can be seen, practice and theory seem to reflect each other. There is uncertainty on the resources that make possible a specific type of recombination, on the resulting low or high DN, and why this 
occurs. Consequently, this work aims at answering these two questions: 1) What are the characteristics of resources and recombinations leading to low and high DN?, and 2) why may resources influence recombinations and, in turn, the DN?

Answering these questions may help practitioners understand if their resources can be innovative. For theoreticians, it can contribute to go beyond novel combinations and be more precise when understanding recombinations. Also, analyzing product innovativeness is relevant as it remains an underexplored area (de Carvalho, Cruz, de Carvalho \& Stankowitz, 2017; Salou, 2004).

With exceptions, specific literature addressing the questions seems fragmented (Fitzgerald, Wankerl, \& Schramm, 2011; Forés \& Camisón, 2016; Kim, Jaeyong \& Nerkar, 2012). Therefore, a critical literature review is necessary to identify literature boundaries. Also, literature synthesis and critical analysis are relevant to develop new knowledge. The method used was an integrative literature review (Torraco, 2016).

New knowledge takes the form of a theoretical model with testable propositions of relations between specific resources and recombinations leading to low DN and high DN. The results suggest that traditional recombinant innovation leads to products closer to low DN. Therefore, novel combinations of existing resources may not be enough for developing more novelty.

This research contributes to practice by suggesting an ex ante assessment roadmap of resources' innovative potential. The theoretical contribution is clarifying resources' role in recombinations and understanding the precise relations creating low and high DN.

The analysis starts by explaining the method for the integrative literature review. Next, critical reviews of each potential model's component (DN, recombinations, and resources) follow. Explorations result in testable propositions. Then, the research puts forward the literature synthesis and discusses it. Finally, the conclusions introduce concluding remarks, theoretical and managerial implications, research limitations, and suggestions for future research.

\section{Method}

Methodology encompassed an integrative literature review for a mature topic such as recombinant innovation. Before deciding on the method, it is necessary to state if there is a need for literature review. According to Torraco (2005), the need for the literature review stems from the idea that "an omission or deficiency in existing literature on an issue is often 
suggested by a discrepancy between the literature and observations about the issue which are not addressed in the literature" (p. 358). This is a situation matching the described gaps in the Introduction. The literature's view on resources, recombinations, and DN may not address the problems companies have for developing a high DN. Additionally, the integrative literature review is a tool suitable for researching a mature topic (Elsban \& Van Knippenberg, 2020), such as the recombinant innovation field, where no additional propositions seem possible.

The integrative literature review matched the study's broad research questions and allowed literature's criticism and synthesis (Snyder, 2019). Thus, new themes emerged for building a new theoretical model (Torraco, 2005). Review implementation was systematic to allow more powerful answers than a single study's (Snyder, 2019) and further research areas' identification to facilitate theory development (Webster \& Watson, 2002; Whittemore \& Knafl, 2005). Next, we describe the steps used to carry out the review and to provide a reference for replicability. We followed the steps indicated by Torraco (2016) due to their applicability to business disciplines:

1. Definition of the conceptual structuring of the topic: The literature on recombinant innovation was the guiding theory (Torraco, 2005) for conducting the review. The review dealt with the literature's approach to DN, recombinations, and resources.

2. Literature search: Based on the conceptual structuring of the topic, the review started by searching journal articles in Google Scholar and EBSCO Host databases. Google Scholar was potentially useful since relying on just one such search platform offered resource efficiency, cost efficiency and allowed quick linking to full texts (Haddaway, Collins, Coughlin, \& Kirk, 2015). EBSCO Host was selected because it is "among the largest and most comprehensive databases for business oriented scholarly full-text journals versus other popular databases" (Downs \& Velamuri, 2016, p. 22). The search was conducted in English, Portuguese, and Spanish. It was unlimited regarding the date and the type of articles due to the fact that the available literature did not fully cover the topic. It also included theoretical and empirical papers. The main keywords for searching were "resources and innovation"; "product novelty"; "recombinations"; "resources and recombinations"; "resources and product novelty"; "resources and knowledge creation"; "knowledge creation and product novelty"; and "recombinations and costs." 
3. Literature selection: From 479 retrieved articles, 145 passed a first-round for inclusion, and 81 were reviewed. The first screening was abstract review-based. The final selection criteria were a possible model component's presence, agreement with questions, and theorizing potential for inferring relations.

4. Literature analysis: The next phase was the analysis of literature. It began by deconstructing questions into possible model components and detecting literature's contributions and weaknesses (Torraco, 2005). Then, the following themes (Miles, Huberman \& Saldaña, 2014; Whittemore \& Knafl, 2005) were classified and identified in the literature: (a) Resource definitions, (b) DN operationalizations; (c) recombinations under risk and uncertainty, (d) recombinations and resources' associated costs and rents, (e) linear or nonlinear innovation processes, (f) resource transformations through recombinations (including time's role, new resource creation, low and high DN development, and local and distant searches), (g) resources' strategic value for recombinations, (h) resource heterogeneity (including sources, knowledge-based and non-knowledge-based resources combinations), (i) resource specificity (including individual asset and inter-asset specificities, and resource complementarity), and (j) resource availability (including quality, quantity, stocks, and flows).

Contrasting and dividing literature perspectives into thematic groups formed a theoretical matrix for analyzing each component. Comparing groups with model assumptions detected the theory's omissions and simplifications (Torraco, 2005). Assumptions served to explain gaps and logically deduce causal relationships (Donaldson, Qiu \& Luo, 2013). For parsimony, the model held only four assumptions about resources, which might: (a) be homogeneous or heterogeneous, (b) promote different recombination types, (c) undergo successive transformations through recombining, and (d) form internally new resources. Explicit assumptions increase a theory's validity and utility (Lynham, 2002; Van de Ven, 1989). Assumptions expose the logic-in-use and reconstruction logic (Kaplan, 2009) that guide the logical reasoning, the proposition development, and the final synthesis into a theoretical model (McGregor, 2018; Whetten, 1989).

5. Creative synthesis: following Torraco (2016), the reviewed literature and the critical analysis were synthesized in a model as a form of integrating the existing literature with the new knowledge derived from the critique. 


\section{Integrative literature review}

\subsection{Degree of Novelty (DN) of a product}

Since novelty is inevitably introduced, any new product has a specific DN. A DN generates discontinuities or changes. Discontinuities occur at the firm and industry levels (Garcia \& Calantone, 2002). Changes at both levels can be technological, commercial, or both.

Low DN products imply little firm and no industry discontinuities (Assink, 2006). Thus, firms do not change much technologically and commercially. Also, they follow the industry's technological paradigm. They propose to existing customers a value similar to competitors' (Chandy \& Tellis, 1998; Koberg, Detienne \& Heppard, 2003). This is typical of product upgrades and line extensions. Developing low DN means recombining and exploiting existing technological and commercial resources (Danneels, 2002). Existing resources are the ones a company can have access to; they can be conceptual and physical assets (Nelson \& Winter, 1982; Schumpeter, 1939).

Based on existing resources and routines, exploitation seeks efficiency (March, 1991). This efficiency offsets lower revenues due to low DN's potential imitability. A longitudinal study of the global pharmaceutical industry by Kim et al. (2012) found out that exploitation leads to a high frequency of new product introduction with a low impact on industry's technology. Frequently, low DN products become obsolete and eventually fail satisfying changing market demands. The reason is the constant reliance on existing firm technologies, as stated by Sørensen and Stuart (2000).

Familiarity with existing resources makes firms knowledgeable of recombination possibilities as resources come from local searching or exploitation (Kang et al., 2019). The recombinant innovation literature contributed importantly by discovering that all new recombinations always start with existing and familiar resources (Kalthaus, 2020). New technologies rely on former technologies for its creation (Dosi \& Nelson, 2013).

However, the question to the literature is what specific DN firms seek with these existing resource recombinations. A systematic literature review by Savino et al. (2015) of 87 empirical recombinant innovation articles shows no explicit mention of the DN concept or how recombinations relate to incremental or radical innovations. A similar situation happened in the recombinant innovation articles we reviewed. Only four articles and one book identify some relations between resources and recombinations with an explicit DN. Kline and Rosenberg (1986) mention a DN continuum between low and high DN and relate a specific 
DN with resources; Ahuja and Lampert (2001) relate radical inventions with firms' resource use and the avoidance of learning traps; Denrell, Fang \& Winter (2003) set a theoretical relationship between novelty and resource use. Arthur $(2007,2009)$ associates the use of resources with radical inventions. However, the studies do not show a clear answer to the research questions.

The remaining reviewed articles show what Garcia and Calantone (2002, p. 110) deem "a plethora of definitions for innovation types." None refers explicitly to the DN as a central concept. For example, some authors talk about innovation in general terms (Adler \& Shernan, 1990; Christensen, 1994, 1996; D'Este, Marzucchi \& Rentocchini, 2017; Kang et al., 2019; Lengick-Hall \& Griffith, 2011; Schriber \& Löwstedt, 2018; Teece, 1986, 2014; Van den Bergh, 2008); technological novelty (Fleming, 2001, Olson \& Frey, 2001); adaptation of existing product patterns (Goldenberg, Mazursky \& Solomon, 1999), product novelty (Katila \& Ahuja, 2002); new solutions (Sun \& Jiang, 2017); and the relation between innovative resources and performance variables, like competitive advantage (Bradley, Sheperd \& Wiklund, 2011; Warnier, Weppe \& Lecocq, 2013).

The point is a nonspecific DN obscures which specific resources are necessary for adding novelty. Literature puts forward knowledge is the answer. An empirical study on analogical thinking for innovation by Gassman and Zeschky (2008, p. 97) supports this view: "innovation entails reassembling elements from existing knowledge bases in a novel fashion."

This perspective's flip side is that the literature seems to consider non-knowledgebased resources as homogeneous and static (Kang et al. 2019). Only knowledge changes through recombinations of different knowledge elements bring novelty (Fleming, 2001; Weitzman, 1998). However, it is unclear how much novelty and whether it is low or high DN. An example suggests literature's recombinations may be related to a low DN. If Unilever had to develop a new Knorr Soup flavor, Unilever would probably 1) rely on existing tangible resources and 2) need few knowledge recombinations (manufacturing and marketing should scarcely change). However, a counterargument to the example could state: "Larger knowledge changes may bring higher DN." The point is how much novelty can be achieved by relying just on knowledge changes.

Garcia and Calantone (2002) conclude that high DN products entail both major industry and firm levels discontinuities. Technological paradigm shifts propose radically new value to new customers (Jansen, Van den Bosch \& Volberda, 2006). Firm changes are large: High DN implies intense recombining and experimenting with new technological and 
commercial resources (Danneels, 2002). Kim et al. (2012) found out that exploratory learning associates with low frequency of new product introduction but high impact on industry's technology. Thus, expected payoffs can be high but so exploration costs (e.g. R\&D activities). The latter can be expensive since results are uncertain and may take years (Gittelman \& Kogut, 2003).

Though some clear criteria exist for defining high DN, the literature, in general, seems inaccurate. A systematic review of 208 articles on disruptive innovation (from 1990 to 2019) found out a "serious misunderstanding and misusing of the concept" (Si \& Chen, 2020, p. 1). In the same way, the recombinant innovation literature curiously also associates high DN to existing resources. Relatedly, for Arts and Veugelers (2015), breakthrough innovations result of reusing familiar components recombining them. For Majchrzak, Cooper and Neece (2004), creating radical innovation implies reusing and exploiting diverse and previously unknown ideas.

Literature also asserts that firms can add more novelty by recombining external new knowledge elements from other industries (Ahuja \& Lampert, 2001). However, the lack of definitions of DN in the literature makes it unclear how high this DN is. Thus, the question is how these new (but existing) resources may add novelty (and what the extent of DN there will be). The thing is that, what the literature calls new external resources are actually existing resources. New external resources already exist in other industries. Since these resources are not firm-specific (Christensen, 2004), competitors can access these resources as well.

The literature calls such resources new because firms are not familiar with them due to the fact that they come from outside the boundaries of the industry (Savino et al., 2015). Gassman and Zeschky's (2008) case study on engineering firms found out that thinking analogically about other industries' ideas successfully applied to developing breakthrough innovations. Echterhoff, Amshoff and Gausemeier (2013) explained how using cross-industry technologies helped developing innovations locally. The literature's claim is that these resources increase novelty by "enhancing the recombinatory set that can be accessed by a firm" (Ahuja et al., 2008, p. 65). However, for achieving allegedly higher DN, it is again clear that the literature cares more about novel recombinations than about resources.

The incorporated "new" resources are still knowledge-based (e.g., new technology). Thus, the view on tangibles resources remains homogeneous. The literature explains that new external resources are transformed and integrated with internal knowledge through absorptive capacity (Forés \& Camisón, 2016). The question is whether these transformed new resources 
are really new or if they are just an attempt to increase a firm's recombinatorial possibilities. So, even for more novelty through new external resources, literature keeps emphasizing novel combinations (Savino et al., 2015). This is clear as several authors acknowledged the real reason for new resources is avoiding technology exhaustion (Fleming, 2001; Olson \& Frey, 2001; Van den Berg, 2008). As technologies mature, new combinations experience marginal diminishing returns (Ahuja \& Lampert, 2001).

To summarize, after this review, we claim that the specific DN achievable with literature's view of homogeneous tangible resources and novel recombinations remains unclear.

\subsection{Recombinations}

When used, resources provide services. Recombinations are the integration of these services to produce new resources supplying additional new services (Penrose, 1959). The final result should be the development of knowledge required for designing new products with a specific DN.

Resource integration (along with intrinsic services) occurs through a repetitive trial and error experimenting process. The literature on this matter explains that knowledge accumulates as repetition occurs (Kang et al., 2019; Kline \& Rosenberg, 1986). A traditional experimenting cycle encompasses a linear sequence of steps: experiment design, prototype construction, testing, and result analysis. Steps and cycles' frequency carry costs (Thomke, 1998).

Logically, as recombinations can create a particular type of knowledge leading to a precise DN, recombinations must also be specific. Thus, depending on the DN a company seeks, issue lies on establishing differences for recombinations. The analysis of literature hints on possible dimensions.

1) The type of resources seems to be a relevant dimension. Through the services resources provide, they may influence the variety of recombinations (Weitzman, 1998, Zeppini \& Van den Bergh; 2013). Recombinations can have similar or diverse services to integrate. Literature relates existing familiar resources to low and high DN indistinctly (Arts \& Veugelers, 2015). This apparent contradiction leads to considering whether new resources play a role in recombinations.

2) The risk or uncertainty level that recombinations face also implies a dimension (Foss \& Klein, 2012). Recombining familiar resources means innovators relatively 
know (risk) the probable innovation results. However, when recombining new resources, uncertainty means these probabilities are unknown (Teece et. al, 2016).

3) Time devoted to search for resources and to integrate them is another dimension. It may impact on the frequency or number of recombinations (Denrell et al., 2003; Fitzgerald et al., 2011). Familiarity reduces the time devoted because these resources may create minor firm discontinuities, which is a typical characteristic of low DN (Garcia \& Calantone, 2002). Literature reinforces the idea that time is an issue also for high DN. Unfamiliar resources to create substantially new knowledge may take years. Arthur (2009) explains penicillin took 13 years from discovery to commercialization.

4) Efficiency is a dimension that gets an impact from the other dimensions. For example, as we will see, familiarity, short time, and risk level should reduce costs. Exploitation may apply to low DN recombinations by reducing costs to face potential lower market impact (Kim et al., 2012). Exploration may apply to high DN recombinations by raising costs due to long recombination time and resource waste (Arthur 2009).

Let us see how these recombinations' dimensions apply to developing low and high DN: Low DN recombinations use existing, familiar, and locally searched resources (Kalthaus, 2020). The Knorr Soup example shows minor discontinuities may justify untransformed tangible resources and changing knowledge (but not substantially) (see Figure 1).

\section{Figure 1}

\section{Low DN recombinations}

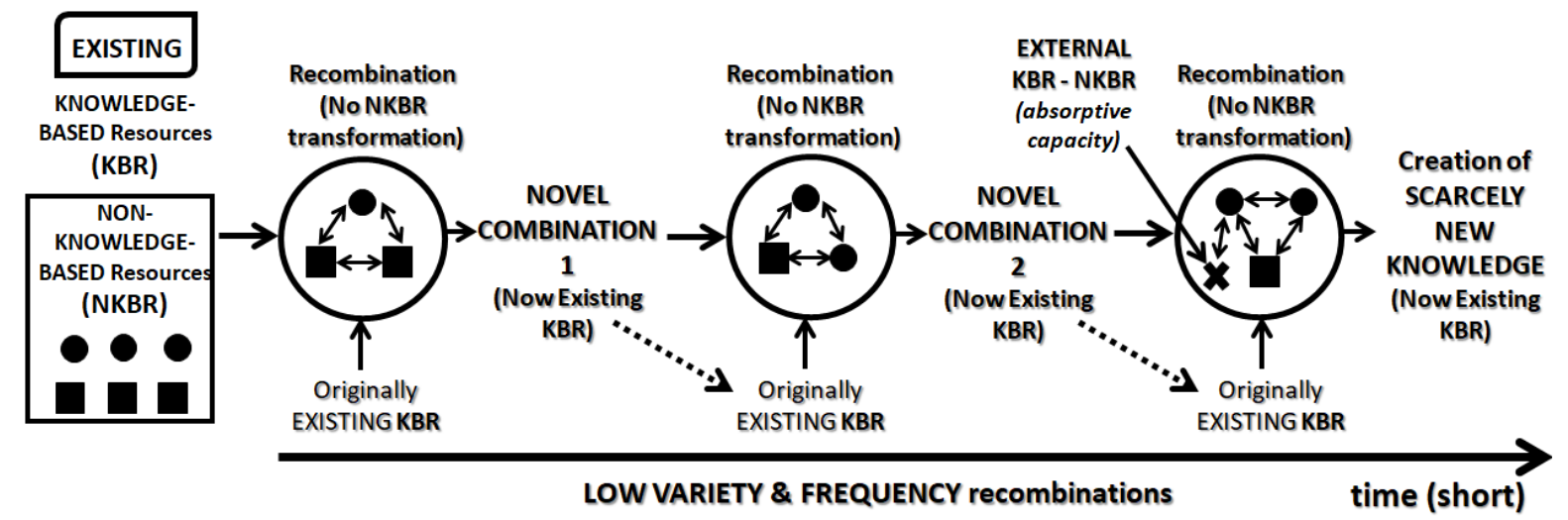

Source: Elaborated by the author. 
Little resource changes should restrict variety of recombinations. This restriction limits the diversity of services for integration. For Van den Bergh (2008), a large scale of similar resources decreases costs. Building diversity increases them by preventing scale construction. Literature's view of knowledge as a specialized stock suggests it provides depth to the knowledge base (Kang et al., 2019). As Katila and Ahuja (2002) found out, depth measures a firm's frequency of reusing the existing knowledge. Through absorptive capacity, some external new resources may participate in recombinations, but occasionally.

When recombinations face risk, efficiency is also further increased. Exploitation predominates (March, 1991) when there is familiarity between resources and recombination outcomes (Ahuja \& Lampert, 2001). Then, firms can assess ex ante an optimal use of resources (Foss \& Klein, 2012; Teece et al., 2016). They can plan and prevent resource waste.

Predictability makes experimenting cycle steps run orderly and linearly (Godin, 2017) without back and forth iterations. Experimentation time shortens, and efficiency increases (Popadiuk \& Choo, 2006). The reduction of time can limit the recombination possibilities. Thus, the frequency of recombinations would be reduced saving additional costs.

To summarize, low variety and frequency of recombinations may limit learning opportunities. Thus, the situation suggests the created knowledge would be scarcely new, and linked to low DN. Several features of low DN recombinations (e.g., novel combinations of existing knowledge-based and unchanged non-knowledge-based-resources) resemble those of the recombinations in the literature.

Next, speaking of high DN recombinations, it is important to differentiate the type of resources used from those recombined when seeking low DN. By overlooking tangible resources, literature may miss their potentially relevant interaction with knowledge for developing high DN. Nonaka (1994) found out that knowledge crystallizes into new physical forms for testing the feasibility of a created concept. Jaccard and Jacoby (2020) state that, although human beings use ideas to define reality, the empirical world resists and poses obstacles. Padfield and Lawrence (2003) describe how, over the years, the Wright brothers developed numerous new and intermediate resources (e.g. new parts) for intermediate prototypes.

In high DN recombinations, these new resources (knowledge and non-knowledgebased) are intermediate inputs for successive recombinations. For literature, resources become complex as they keep building on former resources (Arthur \& Polak, 2007; Denrell et al., 2003). The process means physical resources interact with knowledge recursively: 
Solutions are proposed - and fail; parts do not work; redesigns are necessary; and endless tests must be made. The process becomes a progressive advance across a broad front as knowledge is gained and subtechnology challenges are successively resolved, always pressing toward a version that works properly. (Arthur, 2007, p. 282)

This recursive process involves a constant addition of variety to recombinations through new intermediate resources (see Figure 2). In order to achieve such goal, it also integrates new external resources through absorptive capacity (Gassmann \& Zeschky, 2008). Forés and Camisón (2016) found out that only absorptive capability relates to radical innovation, and internal knowledge can only create low DN. By focusing only on knowledge, these authors overlook the interaction between knowledge and tangible resources. We agree with Forés and Camisón (2016) on internally created novelty. However, internally created resources may have a higher degree of novelty. Inglis and Couples (2020) describe how John L. Baird, the inventor of mechanical television, could not find a powerful enough signal amplifier in the market. TV amplifiers did not exist. He custom-designed and built the video amplifier using owned internal resources: An intermediate part unheard before him.

\section{Figure 2}

High DN recombinations

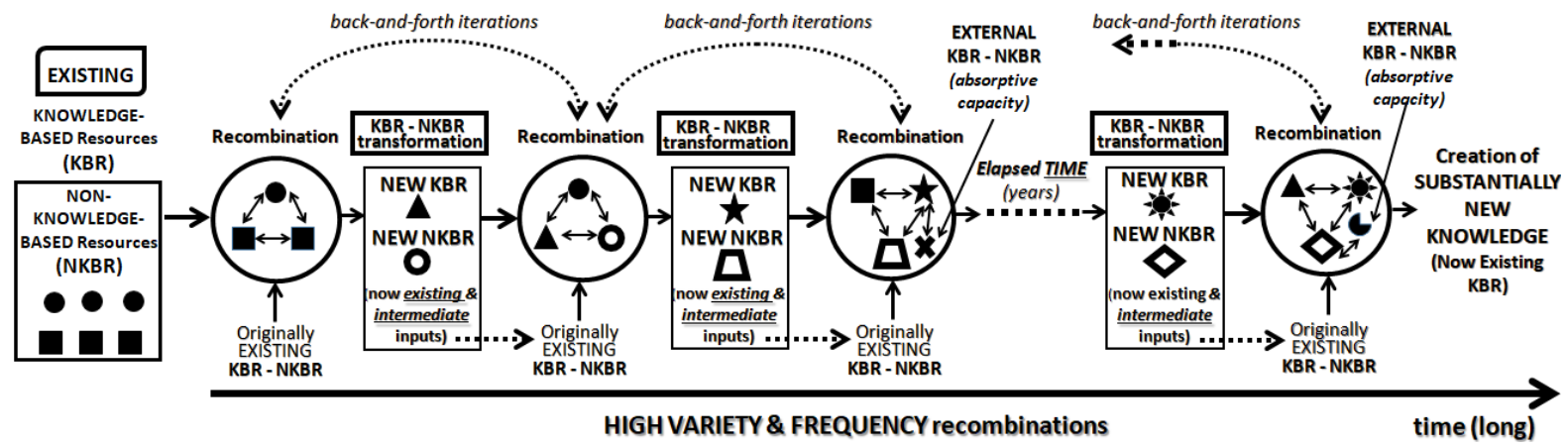

Source: Elaborated by the author.

Thus, the new resources may be externally or internally generated. The demand for high resource variety through intermediate, new, and transformed resources could be continuous. Therefore, a high recombination frequency is essential for running the recursive integrations. The downside is this process creates inefficiency. Developing diverse resources hinders gaining scale returns from similar resources (Zeppini \& Van den Bergh, 2013).

Uncertainty also adds inefficiency to high DN recombinations. Fitzgerald et al. (2001) describe a 20-year technology innovation process for integrated circuits meant exploration and constant iterations with many new resources, unknown at first. This situation may prevent 
firms from assessing resources' innovative potential ex ante (Foss \& Klein, 2012; Teece et al., 2016). Thus, resource planning is non-viable, and iterations make resource waste widespread.

Unpredictability increase inefficiency by destroying the linearity of the experimenting cycle steps (Godin, 2017, Thomke, 1998). There are numerous back and forth iterations over a number of years (Micaëlli, Forest, Coatanéa \& Medyna, 2014; Popadiuk \& Choo, 2006). Logically, the long process increases the costs as it requires a very high recombination frequency.

To summarize, recombinations with high variety and high frequency provide many learning instances. Instances allow a long and gradual creation of knowledge, which may be substantially new to support a high DN (Kalthaus, 2020, Kang et al., 2019).

Finally, as well as the low DN recombinations resemble the typical novel recombinations in the literature (see Figure 1), the critical analysis allows a more accurate model for high DN recombinations (see Figure 2). In a way, it is a comparison between an empirically based model from the literature and a hypothetical model from the critical analysis. The high DN recombination model is an extension beyond the limits of the literature. By briefly comparing low and high DN recombinations, they show differences in the four identified dimensions: Resources types (familiar, untransformed vs. new, intermediate, transformed), the level of risk (risk vs. uncertainty), time (short, linear vs. long, non-linear), and efficiency (low costs vs. high costs). Differences allow developing two clear recombination dimensions, such as variety and frequency. Both dimensions seem to relate to diverse new knowledge types and DN types as they create a different number of chances for learning.

Thus, based on the previous analysis, the propositions are:

(P1): Low variety and frequency recombinations relate to low DN.

(P2): High variety and frequency recombinations relate to high DN.

\subsection{Resources}

In the literature, there are recurrent appearances of common features when referring to resources. A pattern of three possible characteristics shows up: Resource heterogeneity (or resource diversity), specificity (or resource specialization to integrate with other resources), and availability (or resource accessibility).

Studies show resource heterogeneity may occur at different levels: Inter-firm (Ahuja 
\& Katila, 2004; West III \& DeCastro, 2002), intra-firm (Van den Bergh, 2008; Zeppini \& Van den Bergh, 2013), and intra-resource levels (Ahuja \& Lampert, 2001; Christensen, 2000). Moreover, literature focuses on inventions and technology resources (Kalthaus, 2020; Van den Bergh, 2008), but some studies consider source heterogeneity (Fitzgerald et al., 2011), like commercial and organizational ones (Forés \& Camisón, 2016; Laursen \& Salter, 2006).

Besides, resources can have different specificities as their allocation may be in diverse or specialized activities (De Vita, Tekaya, \& Wang, 2011). Some resources (e.g., human and physical) can have strong specificities (Dibbem, Chin \& Heinzl, 2005; Morill \& Morill 2003; Williamson, 1983). Thus, assets can have individual specificities (Schoemaker, 1990; Williamson, 1979, 1981). However, resources can also be specific to others, as there are varying inter-resource complementarities (Christensen, 2000; Kalthaus, 2020). Specificity also varies as resources apply to exploitation or exploration activities (D'Este et al., 2017; Lengnick-Hall \& Griffith, 2011).

Resources may also vary in terms of availability of quantity and quality (Bradley et al., 2011; Schriber \& Löwstedt, 2018). Different availabilities change stock building and maintenance costs (D'Este et al., 2017; Kang et al., 2019; Zeppini \& Van den Bergh, 2013), new product development time, and resource path dependence (Wenzel, 2015; West III \& DeCastro, 2002).

It is relevant that the same literature that treats recombined resources as homogeneous provides some features that show differences among them. However, these studies have a problem as they do not relate these diverse characteristics to specific dimensions of recombinations. An example illustrates why these characteristics may be relevant to explain resource effects on the variety and frequency of recombinations. Weitzman (1998) describes how Thomas Edison's burned 6,000 existing materials until finding the right one to build the incandescent lamp's carbon filament. From Weitzman's (1998) recombinant innovation perspective, Edison combined, in novel ways, pre-existing ideas (i.e., a filament search) implementing them through non-knowledge-based resources (i.e., materials) always malleable and suitable for knowledge-based recombinations. However, the assumed malleability overlooks why resource characteristics could ease or hinder frequency and variety of recombinations. The question is why different levels (low, medium, or high) of heterogeneity, specificity, and availability could do so. In the example provided, the high variety of recombination (i.e., 6,000 materials) and frequency (i.e., 6,000 trials) are evident. However, what would have happened to Edison's combinations without very heterogeneous resources 
providing different services, unspecific enough to facilitate integration with other elements of the lamp prototype, or too readily available to sustain numerous trials? It is likely that for Edison, diverse levels of the three resource characteristics would have had a different impact on variety and frequency (and thus on the level of DN).

As the example shows, a probable relation between characteristics and recombinations exists. Next, it follows an analysis of how and why this may happen. For the sake of simplicity, it focuses on the low and high levels of characteristics:

\subsubsection{Heterogeneity}

Heterogeneity refers to the service diversity the resources bring to recombinations. Low heterogeneity resources may restrict variety of recombinations if they limit the diversity of services to integrate. This characteristic matches the view literature holds about knowledge depth (Kang et al., 2019). Arts and Veugelers (2015) and Majchrzak et al., (2004) agree on reusing knowledge in novel ways. Resources change little, so low heterogeneity supports familiarity. It is likely that, as Zeppini \& Van den Bergh (2013) suggest, large scale of similar resources discourages diversity and breeds efficiency. Satisfied practitioners with resources' usual services will not seek new services or resources from unfamiliar sources (Fitzgerald et al., 2011). According to D'Este et al. (2017), the use of resources would be experience-based.

Experience may reduce recombination risk and facilitate planning (Teece et al., 2016). Substituted by experience, the time devoted to experimentation will reduce substantially (Kang et al., 2019). Hence, a low recombination frequency would suffice as more recombinations of similar resources produce diminishing results. Ahuja and Lampert (2001) hold a similar argument about the stagnation effects of technological exhaustion.

As for high heterogeneity resources, they may increase the variety of recombinations by adding large diversity of services to integrate. Services may come from varied sources: technological, commercial, organizational (Kyriakopoulos, Hughes \& Hughes, 2015) and different resources types (knowledge and non-knowledge-based). The literature's focus on knowledge resources makes it difficult to explain the diversity of sources (Lengick-Hall \& Griffith, 2011).

Practitioners may also create high heterogeneity by imagining how ordinary existing resources can provide new services (Foss \& Ishikawa, 2007; Lewin, 2011). A description of Baird's first mechanical TV system illustrates the point: "The optical system was composed of lenses out of bicycle lamps. The framework was an unimpressive erection of old sugar 
boxes and the electrical wiring a nightmare cobweb of improvisations" (Burns, 2000, p. 75). However, the feasibility of the new services imagined is uncertain, so experimenting is necessary to prove it (D'Este et al., 2017). If so, the variety of recombinations may increase. Following Kang et al. (2019), the knowledge accumulated through experimentation may occur over a whole process of many recombinations. Arthur (2009) complements this by explaining a recursive development of high heterogeneity through new intermediate resources formation. Thus, they often add recombination variety. Also, transforming new external resources by absorptive capacity could add high heterogeneity (Forés \& Camisón, 2016).

High heterogeneity may uncertainly and unpredictably develop during a long time of back and forth iterations. Thus, the exploration process becomes inefficient (Van den Bergh, 2008). It needs several integration opportunities for the frequently incoming new services. Thus, high heterogeneity may lead to high frequency of recombinations.

Heterogeneity may impact all dimensions of recombinations for low and high DN, including a likely influence on efficiency. Therefore, effects on both variety and frequency are expected. However, heterogeneity can be a necessary but not sufficient cause, as other resource characteristics' influences on variety and frequency are likely to take place (Dul, 2016).

Thus, based on the previous analysis, the propositions are:

(P3): Low heterogeneity is necessary for low variety and frequency of recombinations. (P4): High heterogeneity is necessary for high variety and frequency of recombinations.

\subsubsection{Specificity}

Specificity means whether the flexibility of a resource facilitates its use in several tasks or a single activity. A specific resource is that one which is more valuable for specialized uses than it is for non-specialized tasks (Williamson, 1979). The more specialized the services of a resource are, the harder it will be to integrate them with other services of resources.

High specificity resources may decrease variety of recombinations as they provide very specialized services (Lewin, 2011). Resources become very specific over time transforming from generic to use-specific and firm-specific (Christensen, 2000; Schoemaker, 1990). Transformation carries sunk costs to develop very efficient resources (Ghemawat \& 
Del Sol, 1998). Thus, firms value applying them, especially in exploitation (March, 1991). Use in exploration carries high opportunity costs due to a likely limited recombination value (Williamson, 1981). High specificity resources combine mainly with resources with strong known complementarity or inter-asset specificity (Christensen, 1996; Schriber \& Löwstedt, 2018). Thus, specialization and complementarity suggest a low number of services to integrate, reducing variety of recombinations.

Highly specific services should increase recombinations efficiency substantially. Specialized and homogeneous resources from the literature view (Savino et al., 2015) indicate static, unchanged resources. Low change supports familiarity, predictability and risk conditions, and short recombination time. Therefore, no additional recombinations would be warranted, which means that a low frequency of recombinations is probable.

As for low specificity resources, they could increase the variety of recombinations, as they are flexible and provide many services in various uses, which increases their value for exploration. Potentially, resources have multiple specificities unknown ex ante (Lachmann, 1956). If practitioners imagine new integrations among resources must experiment to confirm their feasibility (D'Este et al., 2017). When done, new services may increase variety of recombinations. Low specificity, as high heterogeneity, may help to recursively produce new intermediate resources. Easy integration of new services simplifies the transformation. Baird's TV system parts show how low specificity allows recombinations of tangible resources originally unrelated. This issue contradicts the literature's view of homogeneous tangible resources incapable of recombining with other tangibles (Savino et al., 2015). However, searching for multiple specificities could be uncertain, unpredictable, and lengthy. So, low specificity may add inefficiency to recombinations. Frequent back and forth iterations suggest a necessary high frequency of recombinations. Seeking multiple specificities implies learning how to integrate them with other resources' services.

In short, specificity may impact the four dimensions of recombinations for low and high DN, including a likely influence on efficiency. Both effects on variety and frequency may be likely to occur. However, along with heterogeneity, specificity could be a necessary but insufficient cause for influencing variety and frequency (Dul, 2016).

Thus, based on the previous analysis, the propositions are:

(P5): High specificity is necessary for low variety and frequency of recombinations.

(P6): Low specificity is necessary for high variety and frequency of recombinations. 


\subsubsection{Availability}

Availability refers to the access to resources' quality and quantity a particular recombination type requires. Quality availability refers to diversity at hand (i.e., heterogeneity and associated services). Low quality availability means stocks carry relatively similar generic and firm-specific resources (Christensen, 2000). Similarity breeds low service diversity; then, low quality availability may relate to a low variety of recombinations. Lack of access to a certain resource type parallels literature's homogeneous view restricting availability to just homogeneous resources' services. The limited variety of services coincides with the causes of technology exhaustion in the literature (Ahuja \& Lampert, 2001; Arts \& Veugelers, 2015).

Low quality availability favors risk-based recombinations since an innovator knows the potential outcomes of using a limited number of specific services. Thus, efficiency is improved by promoting familiarity and reducing recombination time.

Low quantity availability refers to the scarce number of resources for recombinations. Thus, it should decrease frequency because of insufficient resources for supplying recombinations. It is a similar picture to running out of effective novel combinations, for example, due to technology exhaustion (Olson \& Frey, 2001). Limited stocks only support efficient, short time, wasteless recombinations, running under risk conditions. Likely, generic, existing, and market available resources make up the scant stocks (Lee \& Barney, 2018).

In terms of high availability characteristics, companies accessing various types of resources showcase high quality availability, which may increase variety of recombinations as it provides a high number of diverse services. Initial supply of high quality availability most likely comes from initial, generic, and commercially available resources (Lee \& Barney, 2018). As recombinations progress, high quality availability should come from new intermediate resources (Schriber \& Löwstedt, 2018). As Van den Bergh (2008) shows, inefficiency occurs when firms invest in diversity. The situation is similar to the costs of high heterogeneity in terms of transforming resources into new ones.

High quantity availability may be necessary for increasing high frequency of recombinations. A recursive process of resource transformation demands a lengthy and continuous supply of resources. Process uncertainty and likely resource waste put pressure on stocks and may lead to inefficiency (Denrell et al., 2003; Kline \& Rosenberg, 1986).

Availability may impact all dimensions of recombinations for low and high DN, including a likely influence on efficiency. Therefore, effects on both variety and frequency are 
expected. However, availability can be a necessary but not sufficient cause, as other influences from other characteristics of resources on variety and frequency are likely to happen (Dul, 2016).

Thus, based on the analysis, the propositions are:

(P7): Low availability is necessary for low variety and frequency of recombinations. (P8): High availability is necessary for high variety and frequency of recombinations.

\section{Resource-related costs' effects}

Previous analyses show different resource characteristics may form configurations, which seem to produce similar effects on frequency and variety of recombinations. According to $\mathrm{P} 3, \mathrm{P} 5$, and $\mathrm{P} 7$, a resource showing low heterogeneity, high specificity, and low availability should facilitate low variety and frequency of recombinations (see Figure 1). According to P4, P6, y P8, a resource showing high heterogeneity, low specificity, and high availability should favor high variety and frequency of recombinations (see Figure 2). The first configuration seems to relate to low DN recombinations, as well as the second configuration corresponds to high DN recombinations.

The question is why the individual characteristics of each configuration may show similar effects on variety and frequency. The analysis of resources provides a plausible answer. Each characteristic seems to impact the efficiency of recombinations by influencing resource familiarity, risk level, and recombination time in the same direction.

The characteristics of the first configuration (low heterogeneity, high specificity, and low availability) may improve efficiency by having a cost-decreasing effect on recombinations. The characteristics of the second configuration (high heterogeneity, low specificity, and high availability) may decrease efficiency by having a cost-increasing effect on recombinations.

Based on the analysis of recombinations and resources, three potential types of resource-created costs seem to be, at least, possible: 1) Costs of the resources for their acquisition (transaction costs); 2) costs created by the resources and their services measured by the learning about the resources' potential for recombination (learning costs); and 3) costs generated by the services of the resources when integrating and creating new resources (integration costs). 
We suggest that different levels of each feature may cause particular costs. These costs may moderate the relation between characteristics from a resource and the variety and frequency of recombinations. To analyze this moderation, we used the "stronger than heuristic" that Jaccard and Jacoby (2020) proposed. It is a way to compare how different sets of costs could relate diverse resource characteristics to different frequencies and varieties.

Resources showing low heterogeneity, high specificity, and low availability may indicate low recombination potential to create new resources. Thus, they may save recombination costs due to high variety and frequency.

The low variety and frequency of recombinations should reduce transactions costs. A local search for familiar resources saves looking for alternatives resources and suppliers. Firms refrain from negotiating and monitoring new contracts (Foss, Foss \& Klein, 2018). Low heterogeneity implies purchased resources are similar to those regularly used, saving searching costs. High specificity reduces transaction costs because specificity development is internal to an organization, and these resources do not redeploy to non-specific uses, reducing internal transactions (De Vita et al., 2011). Low availability reduces transaction costs too. Low availability of quality requires buying a few habitual resource types. Low availability of quantity means limited market transactions.

Firms' resource familiarity may reduce learning costs. Low heterogeneity means firms are already familiar with added resources as they are similar to those usually recombined (D'Este et al., 2017). High specificity suggests firms do not learn new uses as they know resources' specialized services (Foss \& Ishikawa, 2007) and do not seek multiple specificities (Lewin, 2011). Low availability of quality means knowledge about a few existing resource types suffices. The need for low quantity availability avoids learning about new suppliers.

Integration costs may decrease because service combinations do not change much. It is not necessary to seek new inter-asset specificities to recombine. Low heterogeneity implies similar resource characteristics restrict new integration types. High specificity resources combine with well-known complementary ones (Christensen, 2000; Kang et al., 2019). Low availability of exploration resources limits new recombination and integrations types.

As for the second configuration, resources with high heterogeneity, low specificity, and high availability may increase recombination costs. The potential characteristics have to create new resources implies high costs due to high frequency and variety.

High variety and frequency in recombinations may increase transactions costs. Firms seek novel resources and suppliers and must negotiate and monitor contracts (Foss et al., 
2018). High heterogeneity usually implies adding new heterogeneous resources through distant searches what increases transactions (Echterhoff et al., 2013). When getting resources for multiple specificities seeking, low specificity increases transactions costs related to redeploying exploitation resources and to buying generic resources (Lewin, 2011; Williamson, 1981). High availability of quality and quantity for meeting the continuous demand of resources by the recombinations requires relying on many transactions.

Inexperience regarding new resources may increase learning costs. Having many highly heterogeneous new resources involves that firms need to know their usefulness. Low specificity means new uses from multiple specificities that companies may not be familiar with (D'Este et al., 2017). High quality and quantity availability require learning, before and throughout recombinations, on new resource features and alternative suppliers (even in other industries).

In addition, new services may also increase integration costs. High heterogeneity increases the complexity of recombinations (Arthur \& Polak, 2006) by adding many more new resources and uses to integrate. Low specificity requires more experiments to discover inter-asset specificities for the new uses from multiple specificities (Kang et al., 2019). These experiments rely on continuous high availability of quality and quantity to avoid delays.

For both configurations, the characteristics a resource has and the recombinations they enable seem to have a direct relationship. Thus, any resource participating in any recombination type should always have a specific level of these features. Similarly, there is a possible direct relationship between the characteristics of a resource and recombination costs.

Thus, based on the previous analysis, the propositions are:

(P9): Low heterogeneity, high specificity, and low availability from resources reduce recombination costs.

(P10): High heterogeneity, low specificity, and high availability from resources increase recombination costs

(P11): Low recombination costs associate with low variety and frequency of recombinations.

(P12): High recombination costs associate with high variety and frequency of recombinations. 


\section{Synthesis and discussion}

Previous sections answered the first research question. The literature review described resources as familiar, existing, and external new ones, without clearly relating them to a specific DN. Also, it helped to identify heterogeneity, specificity, and availability as characteristics of knowledge and non-knowledge-based resources. However, the connection between features and specific recombination types is also unclear. These gaps made critical analysis necessary for explaining that these characteristics may also have low and high levels related to recombinations seeking low and high DN. Thus, it differentiated the configurations influencing the variety and frequency of these recombinations. In addition, the critical analysis identified the dimensions of recombinations (type of resources, level of risk, time, efficiency) and low and high variety and frequency as defining concepts of recombinations.

On the second research question, the Resources section explains why costs generated by configurations may influence the variety and frequency of recombinations (see Figure 3).

\section{Figure 3}

The RRD (resources, recombinations, DN) model

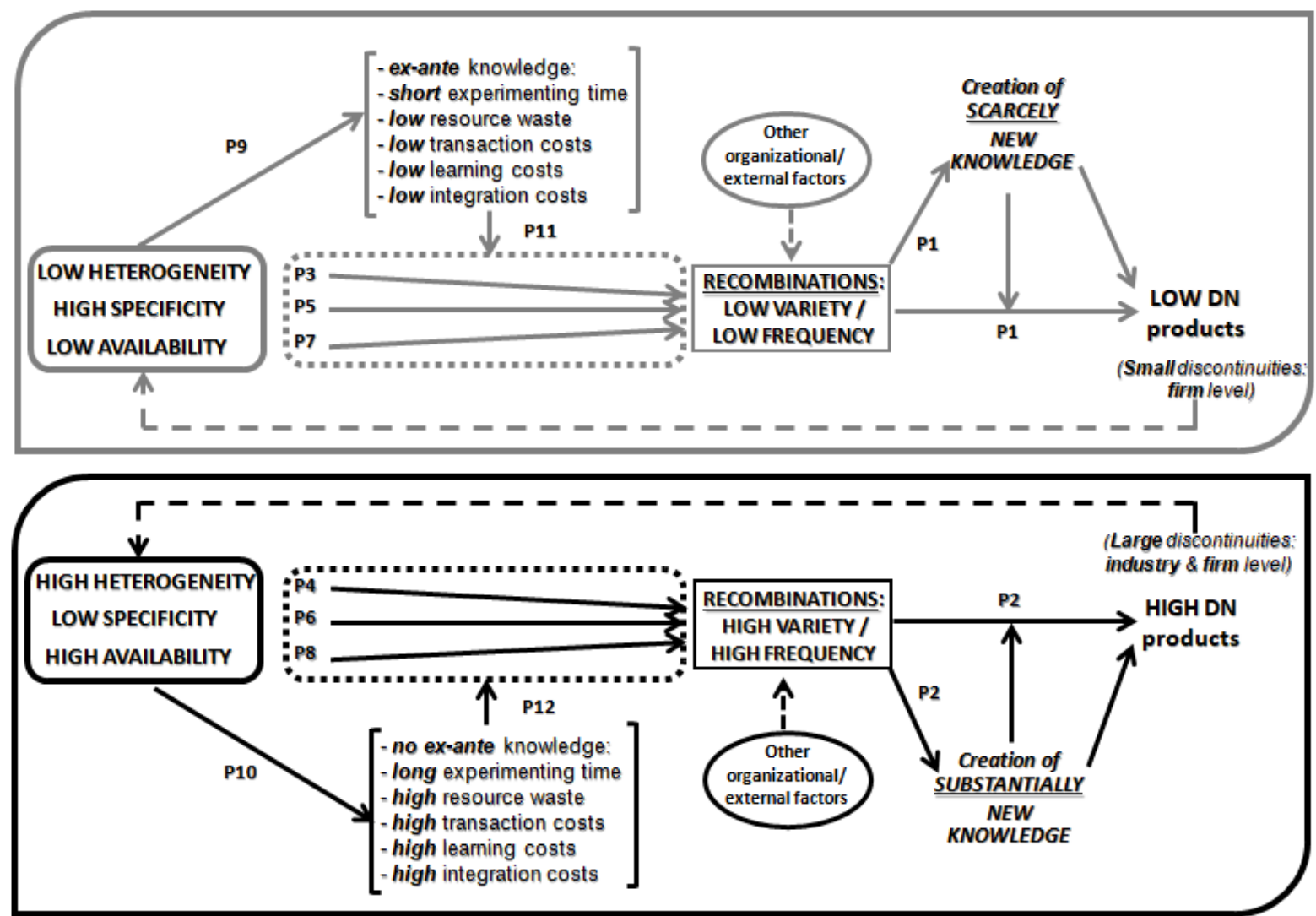

Source: Elaborated by the author. 
An additional influence on the variety and frequency of recombinations would be the impact of resource characteristics on their efficiency. A reconstruction of previous analyses and propositions took the form of a model's path diagram (called the RRD model for resources, recombinations, and $\mathrm{DN}$ ) to explain the relationships between resources, recombinations, and DN (see Figure 3). The model shows precise relations between a configuration of the characteristics of a resource, a definitive cost set, a particular recombination type, and a certain new knowledge kind, ending in a specific DN.

The individual characteristics of resources related to heterogeneity (P3 or P4), specificity (P5 or P6), and availability (P7 or P8) may be necessary but not sufficient to influence recombinations (Dul, 2016). These characteristics may apply to both knowledge and non-knowledge-based resources. Each feature seems to produce a similar effect (low or high) on the variety and frequency of recombinations. Therefore, the characteristics of resources may be equifinal (Schneider \& Wagemann, 2012). The configuration they form could produce complex effects on variety and frequency.

The three characteristics of a resource could also show additional equifinality. Features from the same configuration could create a system of similar costs and efficiencies (P9 and P10). This system seems to moderate (Jaccard \& Jacoby, 2020) the model's direct relationship between the resource features and the variety and frequency of recombinations. Low costs and high efficiencies may attenuate resource characteristics' effects by decreasing both variety and frequency (P11). High costs and low efficiencies may amplify effects of the characteristics of resources by increasing both variety and frequency (P12).

Also, each recombination type creates a particular kind of new knowledge (scarcely and substantially new) associated with a specific DN. The different knowledge types may mediate the recombinations-DN relationship (P1 or P2). They also relate directly to a particular DN.

To make low and high DN development processes comparable, the representation of recombinations in the model intentionally omits the time effect. For the sake of simplicity, the model leaves out recombinations' intermediate inputs and non-knowledge-based resources (though they are an essential part of the model- see Figures 1 and 2). The only represented resource is new knowledge. The reasons are twofold. First, the final result of a recombination process is new knowledge creation (Popadiuk \& Choo, 2006). Second, knowledge is the main element for designing new products and achieving a specific ND (Savino et al., 2015; Sheremata, 2000). 
The accuracy of the relations of the model suggests limitations of a homogenizing view on resources and recombinations. The characteristics of both concepts may vary under precise circumstances, including the conditions of risk and uncertainty. Specific resource features may set boundaries about the type of recombination and the DN they facilitate or not.

The recombinant innovation homogeneous view seems to apply for seeking low DN based on existing, generic untransformed resources and external new resources (Arts \& Veugelers, 2015; Kalthaus, 2020) but not for seeking high DN (see Figure 1).

However, resources, especially non-knowledge-based ones, do not seem to be perfectly malleable by any novel combination of knowledge (Savino et al., 2015). In a different fashion from recombinant innovation (Majchrzak et al., 2004; Teece et. al., 2016), the model emphasizes the potential importance of non-knowledge-based resources. It also stresses the role of new intermediate resources for creating novelty in high DN-seeking recombinations (see Figure 2).

Unlike traditional recombinant innovation, high DN development recombinations may not be just knowledge-based (Kang et al., 2019). Knowledge is still essential. However, the interaction of knowledge with non-knowledge-based resources seems relevant to transform each other to produce intermediate, internally generated resources of both types (Schriber \& Löwstedt, 2018). Without these really new resources, technological exhaustion (Ahuja \& Lampert, 2001) may eventually occur. Adding external resources (Fleming, 2001) may create limited novelty as they are still existing ones. This addition may not solve the apparent continuous need for transforming resources internally to develop new intermediate ones. This necessity may happen even with an available and developed absorptive capacity, since this one needs mainly external resources to perform (Forés \& Camisón, 2016). Like learninginnovation performance literature states (Kim et al., 2012), internal new resources may add novelty in addition to external resources (Echterhoff et al., 2013; Gassmann \& Zeschky, 2008). However, from a different perspective from the one held by this literature, internal new resources are not just limited to low DN seeking. These resources seem to be relevant contributors to high DN seeking.

Innovation is a multidimensional phenomenon (Lu, Cui \& Zhang, 2018). Thus, the model also includes possible disturbance terms (Jaccard \& Jacoby, 2020), which beyond analyzed factors may also influence variety and frequency. These terms are additional unanalyzed organizational and external variables (e.g., organizational structure, strategy, competitive environment, etc.). Finally, the model also reflects the DN likely influences 
reciprocally the path-dependence of resources (Wenzel, 2015) to use in a future recombination process.

To summarize, the model shows apparent linear relations (D’Este et al., 2017; Katila \& Ahuja, 2002), but its focus on equifinality and time effect departs from recombinant innovation linearity (Majchrzak et al., 2004; Schriber \& Löwstedt, 2018). The equifinalities and the cost system show systemic effects in recombinations may be relevant ( $v s$. mere linear effects of one variable influencing another). Costs for recombinations are not explicitly considered in the literature but seem critical to elucidate firms' disparate innovation potentials (Zeppini \& Van den Bergh, 2013). Unlike the linear view of recombinant innovation (Godin, 2017), according to the model, time is essential for seeking high DN (see Figure 2). Time is necessary for developing characteristics of resources absent when recombinations begin (e.g., low specificity), promoting more combinations through high recombination frequency, and adding variety to recombinations through resource transformation (Christensen, 2000).

\section{Conclusions and implications}

The analysis fulfills the goal of answering both research questions. Regarding the first question (What are the characteristics of resources and recombinations leading to low and high DN?), the literature review helped to define these characteristics. Many conceptual categories were implicit. Therefore, the critical analysis helped them to surface to reconceptualize a mature subject. Based on this research, it was also possible to answer the second question (Why may resources influence recombinations and, in turn, the DN?). In order to provide an answer, we followed the synthesis procedure of the review methodology to build a model and testable propositions. The model results in Figure 3 (including recombination models in Figures 1 and 2) reflect the boundaries and contributions of the studied literature.

The propositions had a critical analysis of former empirical research as the basis for their development. However, as a limitation of this research, they are still inconclusive since empirical testing is mandatory. Also, the model does not include other possible environmental and organizational causes of a particular DN (though it acknowledges possible disturbance terms). The complementarity of the model with other determinants is relevant for deeper understanding.

In terms of implications, from a theoretical standpoint, the analysis clarifies some of the roles resources may play in innovation. It does so through specific definitions of 
resources, recombinations, and $\mathrm{DN}$; and through a model that explains a set of relationships that puts resources at the forefront. Proposition-based relations may have predictive theoretical value. By focusing on micro-processes of innovation, the research stresses the relevance of resources for recombinations research. Thus, it expands a mature topic with a new perspective. For professional practice, the research may provide practitioners with an easy-to-understand practical roadmap to evaluate ex ante an innovation project's feasible novelty under conditions of risk and uncertainty.

Regarding future directions for research, it is important to understand, theoretically and empirically, the intermediate positions in the DN continuum, as well as specific resources and recombinations. Additionally, it is relevant to clarify the applicability of the model to different scenarios and industries. Besides, it would be helpful to test the temporal dynamics of the model. Resource characteristics, very likely, would not have an infinite linear effect on the variety and frequency of recombinations.

As final remarks, resources in innovation matter. They are not an amorphous heap. Therefore, a broad and heterogeneous view on them is essential as it may have consequences for developing high novelty products. To this end, this research strived to make significant contributions to the theory and practice of innovation management studies.

\section{References}

Adler, P. S., \& Shernan, A. (1990). Adapting your technological base: The organizational challenge. Sloan Management Review, 31(1), 25-37.

Ahuja, G., \& Lampert, C. M. (2001). Entrepreneurship in the large corporation: A longitudinal study of how established firms create breakthrough inventions. Strategic Management Journal, 22(6-7), 521-543. https://doi.org/10.1002/smj.176

Ahuja, G., \& Katila, R. (2004). Where do resources come from? The role of idiosyncratic situations. Strategic Management Journal, 25(8-9), 887-907. https://doi.org/10.1002/smj.401

Ahuja, G., Lampert, C. M., \& Tandon, V. (2008). Moving beyond Schumpeter: management research on the determinants of technological innovation. Academy of Management Annals, 2(1), 1-98. https://doi.org/10.5465/19416520802211446

Alvarenga, R. (2016). Study of factors contributors to death of micro and small companies in the State of Maranhão. International Journal of Innovation, 4(2), 106-118. http://dx.doi.org/10.5585/iji.v4i2.36 
Arthur, W. B., \& Polak, W. (2006). The evolution of technology within a simple computer model. Complexity, 11(5), 23-31. https://doi.org/10.1002/cplx.20130

Arthur, W. B. (2007). The structure of invention. Research Policy, 36(2), 274-287. https://doi.org/10.1016/j.respol.2006.11.005

Arthur, W. B. (2009). The Nature of Technology: What it is and how it evolves. Free Press.

Arts, S., \& Veugelers. R. (2015). Technology familiarity, recombinant novelty, and breakthrough invention. Industrial and Corporate Change, 24(6), 1215-1246. https://doi.org/10.1093/icc/dtu029

Assink, M. (2006). Inhibitors of disruptive innovation capability: A conceptual model. European Journal of Innovation Management, 9(2), 215-233. https://doi.org/10.1108/14601060610663587

Belenzon, S. (2012). Cumulative innovation and market value: Evidence from patent citations. Economic Journal, 122(559), 265-285. https://doi.org/10.1111/j.14680297.2011.02470.x

Bradley, S. W., Sheperd, D. A., \& Wiklund, J. (2011). The importance of slack for new organizations facing 'tough' environments. Journal of Management Studies, 48(5), 1071-1097. https://doi.org/10.1111/j.1467-6486.2009.00906.x

Buchanan, M. (2015). Innovation slowdown. Nature Physics, 11, 2. https://doi.org/10.1038/nphys3222

Burns , R. W. (2000). John Logie Bair. TV pioneer. MPG Books.

Chandy, R. K., \& Tellis, G. J. (1998). Organizing for radical product innovation: The overlooked role of willingness to cannibalize. Journal of Marketing Research, 35(4), 474-487. https://doi.org/10.1177/002224379803500406

Christensen, J. F (1994). Asset profiles for technological innovation. Research Policy, 24(1995), 727-745. https://doi.org/10.1016/0048-7333(94)00794-8

Christensen, J. F. (1996). Innovative assets and inter-asset linkages: A resource-based approach to innovation. Economics of Innovation and New Technology, 4(3), 193-210. https://doi.org/10.1080/10438599600000009

Christensen, J. F. (2000). Building innovate assets and dynamic coherence in multitechnology companies. In N. J. Foss, \& P. L. Robertson (Eds.), Resource, technology and strategy: Explorations in the resource-based perspective (pp. 123-152). Routledge. https://doi.org/10.4324/9780203982259

Danneels, E. (2002). The dynamics of product innovation and firm competences. Strategic Management Journal, 23(12), 1095-1121. https://doi.org/10.1002/smj.275 
de Carvalho, G. D. G., Cruz, J. A. W., de Carvalho, H. G., \& Stankowitz, R. F. (2017). Innovativeness measures: A bibliometric review and a classification proposal. International Journal of Innovation Science, 9(1), 81-101. http://dx.doi.org/10.1108/IJIS-10-2016-0038

de Carvalho, G. D. G., da Silva, E. D., de Carvalho, H. G., Cavalcante, M. B., \& Cruz, J. A. W. (2017). Brazilian SMEs' innovation strategies: Agro-industry, construction and retail. International Journal of Business Innovation and Research, 14(3), 397-419. https://doi.org/10.1504/IJBIR.2017.087097

De Vita, G., Tekaya, A., \& Wang, C. L. (2011). The many faces of asset specificity: A critical review of key theoretical perspectives. International Journal of Management Reviews, 13(4), 329-348. https://doi.org/10.1111/j.1468-2370.2010.00294.x

Denrell, J., Fang, C., \& Winter, S. G. (2003). The economics of strategic opportunity. Strategic Management Journal, 24(10), 977-990. https://doi.org/10.1002/smj.341

D'Este, P., Marzucchi, A., \& Rentocchini, F. (2017). Exploring and yet failing less: Learning from past and current exploration in R\&D. Industrial and Corporate Change, 27(3), 525-553. https://doi.org/10.1093/icc/dtx044

Dibbem, J., Chin, W.W., \& Heinzl, A. (2005). The impact of human asset specificity on the sourcing of application services. 13th European Conference of Information Systems Proceedings, 114.

Donaldson, L., Qiu, J., \& Luo, B. N. (2013). For rigour in organizational management theory research. Journal of Management Studies, 50(1), 153-172. https://doi.org/10.1111/j.1467-6486.2012.01069.x

Dosi, G., \& Nelson, R. R. (2013). The evolution of technologies: An assessment of the stateof-the-art. Eurasian Business Review, 3(1), 3-46. https://doi.org/10.14208/BF03353816

Downs, J. B., \& Velamuri, V. K. (2016). Business model innovation: Opportunities for the biopharmaceutical industry: A systematic review. Journal of Commercial Biotechnology, 22(3), 19-63. https://doi.org/10.5912/JCB735

Dul, J. (2016). Necessary condition analysis (NCA): Logic and methodology of "necessary but not sufficient'” causality. Organizational Research Methods, 19(1) 10-52, https://doi.org/10.1177/1094428115584005

Echterhoff, N., Amshoff, B., \& Gausemeier, J. (2013). Cross-industry innovationsSystematic identification of ideas for radical problem solving. International Journal of Industrial and Manufacturing Engineering, 7(2), 239-248. https://doi.org/10.5281/zenodo.1083853

Elsban, K. D., \& Van Knippenberg, D. (2020). Creating high-impact literature reviews: An argument for 'integrative reviews'. Journal of Management Studies, 57(6), 12771289. https://doi:10.1111/joms.12581 
Fitzgerald, E., Wankerl, A., \& Schramm, C. (2011). Inside real innovation: How the right approach can move ideas from $R \& D$ to market - and get the economy moving. World Scientific Publishing.

Fleming, L. (2001). Recombinant uncertainty in technological search. Management Science, 47(1), 117-132. https://doi.org/10.1287/mnsc.47.1.117.10671

Forés, B., \& Camisón, C. (2016). Does incremental and radical innovation performance depend on different types of knowledge accumulation capabilities and organizational size? Journal of Business Research, 69(2), 831-848. https://doi.org/10.1016/j.jbusres.2015.07.006

Foss, N. J., \& Ishikawa, I. (2007). Towards a dynamic resource-based view: Insights from Austrian capital and entrepreneurship theory. Organization Studies, 28(5), 749-777. https://doi.org/10.1177/0170840607072546

Foss, N. J., \& Klein, P. G. (2012). Organizing entrepreneurial judgment: A new approach to the firm. Cambridge University Press. https://doi.org/10.1017/CBO9781139021173

Foss, K., Foss, N. J., \& Klein, P. G. (2018). Uncovering the hidden transaction costs of market power: A property rights approach to strategic positioning. Managerial and Decision Economics, 39(3), 306-319. https://doi.org/10.1002/mde.2905

Garcia, R., \& Calantone, R. (2002). A critical look at technological innovation typology and innovativeness terminology: A literature review. Journal of Product Innovation Management, 19(2), 110-132. https://doi.org/10.1016/S0737-6782(01)00132-1

Gassmann, O., \& Zeschky, M. (2008). Opening up the solution space: The role of analogical thinking for breakthrough product innovation. Creativity and Innovation Management, 17(2), 97-106. https://doi.org/10.1111/j.1467-8691.2008.00475.x

Ghemawat, P., \& Del Sol, P. (1998). Commitment versus flexibility? California Management Review, 40(4), 26-42. https://doi.org/10.2307/41165963

Gittelman, M., \& Kogut, B. (2003). Does good science lead to valuable knowledge? Biotechnology firms and the evolutionary logic of citation patterns. Management Science, 49(4), 366-382. https://doi.org/10.1287/mnsc.49.4.366.14420

Godin, B. (2017). Models of innovation: the history of an idea. MIT Press.

Goldenberg, J., Mazursky, D., \& Solomon, S. (1999). Toward identifying the inventive templates of new products: A channeled ideation approach. Journal of Marketing Research, 36(2), 200-210. https://doi.org/10.1177/002224379903600205

Haddaway N. R., Collins A. M., Coughlin, D., \& Kirk, S. (2015). The role of Google Scholar in evidence reviews and its applicability to grey literature searching. PLoS ONE 10(9), Article e0138237. https://doi.org/10.1371/journal.pone.0138237 
Inglis, B. D., \& Couples, G. D. (2020). John Logie Baird and the secret in the box: The undiscovered story behind the world's first public demonstration of television. Proceedings of the IEEE, 108(8), 1371-1382. https://doi.org/ 10.1109/JPROC.2020.2996793

Jaccard, J. \& Jacoby, J. (2020). Theory construction and model-building skills: A practical guide for social scientists (2nd ed.). The Guilford Press.

Jansen. J. J. P., Van den Bosch, F. A. J., \& Volberda, H. W. (2006). Exploratory innovation, exploitative innovation, and performance: Effects of organizational antecedents and environmental moderators. Management Science, 52(11), 1661-1674. https://doi.org/10.1287/mnsc.1060.0576

Kalthaus, M. (2020). Knowledge recombination along the technology lifecycle. Journal of Evolutionary Economics, 30(3), 643-704. https://doi.org/10.1007/s00191-020-00661-z

Kang, T., Baek, C., \& Lee, J. (2019). Effects of knowledge accumulation strategies through experience and experimentation on firm growth. Technological Forecasting and Social Change, 144, 169-181. https://doi.org/10.1016/j.techfore.2019.04.003

Kaplan, A. (2009). The conduct of inquiry: Methodology for behavioral science (4th ed.). Transaction Publishers. https://doi.org/10.4324/9781315131467

Katila, R., \& Ahuja, G. (2002). Something old, something new: A longitudinal study of search behavior and new product introduction. Academy of Management Journal, 45(6), 1183-1194. https://doi.org/10.2307/3069433

Kim, C., Jaeyong, S., \& Nerkar, A. (2012). Learning and innovation: Exploitation and exploration trade-offs. Journal of Business Research, 65, 1189-1194. https://doi.org/10.1016/j.jbusres.2011.07.006

Kline, S., \& Rosenberg, N. (1986). An overview of innovation. In R. Landau, \& N. Rosenberg (Eds.), The positive sum strategy: Harnessing technology for economic growth (pp. 275-306). National Academy of Sciences. https://doi.org/10.17226/612

Koberg, C. S., Detienne, D. R., \& Heppard, K. A. (2003). An empirical test of environmental, organizational, and process factors affecting incremental and radical innovation. Journal of High Technology Management Research, 14(1), 21-45. https://doi.org/10.1016/S1047-8310(03)00003-8

Kogut, B., \& Zander, U. (1992). Knowledge of the firm, combinative capabilities, and the replication of technology. Organization Science, 3(3), 383-397. https://doi.org/10.1287/orsc.3.3.383

Kyriakopoulos, K., Hughes, M., \& Hughes, P. (2015). The role of marketing resources in radical innovation activity: Antecedents and payoffs. Journal of Product Innovation Management, 33(4), 398-417. https://doi.org/10.1111/jpim.12285

Lachmann, L. M. (1956). Capital and its structure. Sheed Andrews and McMeel. 
Laursen, K., \& Salter, A. J. (2006). Open for innovation: The role of openness in explaining innovative performance among UK manufacturing firms. Strategic Management Journal, 27(2), 131-150. https://doi.org/10.1002/smj.507

Lee, L., \& Barney, J. B. (2018). Strategic factor markets. In M. Augier, \& D. J. Teece (Eds.), The Palgrave encyclopedia of strategic management (pp. 519-521). Palgrave MacMillan. https://doi.org/10.1057/978-1-349-94848-2

Lengnick-Hall, C. A., \& Griffith, R. J. (2011). Evidence-based versus tinkerable knowledge as strategic assets: A new perspective on the interplay between innovation and application. Journal of Engineering and Technology Management, 28(3), 147-167. https://doi.org/10.1016/j.jengtecman.2011.03.003

Lewin, P. (2011). Capital in desequilibrium: The role of capital in a changing world. Ludwig Von Mises Institute.

Lu, X., Cui, W., \& Zhang, X. (2018). A multidimensional understanding on innovation problem. Advances in Social Science, Education and Humanities Research, 213, 186192. https://doi.org/10.2991/ichssr-18.2018.36

Lynham, S. A. (2002). The general method of theory-building research in applied disciplines. Advances in Developing Human Resources, 4(3), 221-241. https://doi.org/10.1177/1523422302043002

Majchrzak, A., Cooper, L. P., \& Neece, O. E. (2004). Knowledge reuse for innovation. Management Science, 50(2), 174-188. https://doi.org/10.1287/mnsc.1030.0116

March, J. G. (1991). Exploration and exploitation in organizational learning. Organization Science, 2(1), 71-87. https://doi.org/10.1287/orsc.2.1.71

McGregor, S. L. T. (2018). Understanding and evaluating research: A critical guide. Sage. https://dx.doi.org/10.4135/9781071802656

Micaëlli, J. P., Forest, J., Coatanéa, E., \& Medyna, G. (2014). How to improve Kline \& Rosenberg's chain-linked model of innovation: Building blocks and diagram-based languages. Journal of Innovation Economics and Management, 3(15), 59-77. https://doi.org/10.3917/jie.015.0059

Miles, M. B., Huberman, A. M., \& Saldaña, J. (2014). Qualitative data analysis: a methods sourcebook (3rd ed.). Sage. https://doi.org/10.1080/10572252.2015.975966

Morill, C., \& Morill, J. (2003). Internal auditors and the external audit: A transaction cost perspective. Managerial Auditing Journal, 18(6-7), 490-504. https://doi.org/10.1108/02686900310482632

Mukherjee, S., Uzzi, B., Jones, B., \& Stringer, M. (2016). A new method for identifying recombinations of existing knowledge associated with high-impact innovation. Journal of Product Innovation Management, 33(2), 224-236. https://doi.org/10.1111/jpim.12294 
Nelson, R. R., \& Winter, S. G. (1982). An evolutionary theory of economic change. The Belknap Press.

Nonaka, I. (1994). A dynamic theory of organizational knowledge creation. Organization Science, 5(1), 14-37. https://doi.org/10.1287/orsc.5.1.14

Olson, O., \& Frey, B. S. (2001). Entrepreneurship as recombinant growth. Small Business Economics, 19(2), 69-80. https://doi.org/10.1023/A:1016261420372

Padfield, G. B., \& Lawrence, B. (2003). The birth of flight control: An engineering analysis of the Wright brothers' 1902 glider. The Aeronautical Journal, 107(1078), 697-718. https://doi.org/10.1017/S0001924000013464

Penrose, E. T. (1959). The theory of the growth of the firm. Blackwell.

Popadiuk, S., \& Choo, C. W. (2006). Innovation and knowledge creation: How are these concepts related? International Journal of Information Management, 26(4), 302-312. https://doi.org/10.1016/j.ijinfomgt.2006.03.011

Salou, H. (2004). The concept of innovativeness: should we need to focus? European Journal of Innovation Management, 7(1), 33-44. https://doi.org/10.1002/smj.16010.1108/14601060410515628

Savino, T., Messeni Petruzzelli, A., \& Albino, V. (2015). Search and recombination process to innovate: A review of the empirical evidence and a research agenda. International Journal of Management Reviews, 19(1), 54-75. https://doi.org/10.1111/ijmr.12081

Schneider, C. Q., \& Wagemann, C. (2012). Set-theoretic methods for the social sciences: a guide to qualitative comparative analysis. Cambridge University Press. https://doi.org/10.1017/CBO9781139004244

Schoemaker, P. J. H. (1990). Strategy, complexity, and economic rent. Management Science, 36(10), 1178-1192. https://doi.org/10.1287/mnsc.36.10.1178

Schriber, S., \& Löwstedt, J. (2018). Managing asset orchestration: A processual approach to adapting to dynamic environments. Journal of Business Research, 90(9), 307-317. https://doi.org/10.1016/j.jbusres.2018.05.027

Schumpeter, J. A. (1939). Business cycles. McGraw-Hill.

Sheremata, W. A. (2000). Centrifugal and centripetal forces in radical new product development under time pressure. Academy of Management Review, 25(2), 389-408. https://doi.org/10.2307/259020

Si, S., \& Chen, H. (2020). A literature review of disruptive innovation: What it is, how it works and where it goes. Journal of Engineering and Technology Management, 56(2), 1-21. https://doi.org/10.1016/j.jengtecman.2020.101568

Silva, J. C. L., Braga, C. S. C., \& Rebouças, S. M. D. P. (2016). Perception of the Brazilian manufacturing industry about the main barriers to innovation. International Journal of Innovation, 5(1), 114-131. https://doi.org/10.5585/iji.v5i1.114 
Snyder, H. (2019). Literature review as a research methodology: An overview and guidelines. Journal of Business Research, 104, 333-339. https://doi.org/10.1016/j.jbusres.2019.07.039

Sørensen, J. B., \& Stuart, T. E. (2000). Aging, obsolescence, and organizational innovation. Administrative Science Quarterly, 45(1), 81-112. https://doi.org/10.2307/2666980

Sun, M., \& Jiang, H. (2017). Innovating by combining: A process model. Procedia Engineering, 174(5), 595-599. https://doi.org/10.1016/j.proeng.2017.01.193

Teece, D. J. (1986). Profiting from technological innovation. Research Policy, 15(6), 285305. https://doi.org/10.1016/0048-7333(86)90027-2

Teece, D. (2014). A dynamic capabilities-based entrepreneurial theory of the multinational enterprise. Journal of International Business Studies, 45, 8-37. https://doi.org/10.1057/jibs.2013.54

Teece, D. J., Peteraf, M. A., \& Leih, S. (2016). Dynamic capabilities and organizational agility: Risk, uncertainty, and strategy in the innovation economy. California Management Review, 58(4), 13-35. https://doi.org/10.1525/cmr.2016.58.4.13

Thomke, S. H. (1998). Managing experimentation in the design of new products. Management Science, 44(6), 743-762. https://doi.org/10.1287

Torraco, R. J. (2005). Writing integrative literature reviews: Guidelines and examples. Human Resource Development Review, 4(3), 356-367. https://doi.org/10.1177/1534484305278283

Torraco, R. J. (2016). Writing integrative literature reviews: Using the past and present to explore the future. Human Resource Development Review, 15(4), 404-428. https://doi.org/10.1177/1534484316671606

Van de Ven, A. H. (1989). Nothing is quite so practical as a good theory. Academy of Management Review, 14(4), 486-489. https://doi.org/10.5465/amr.1989.4308370

Van den Bergh, J. C. J. M. (2008). Optimal diversity: Increasing returns versus recombinant innovation. Journal of Economic Behavior and Organization, 68(3-4), 565-580. https://doi.org/10.1016/j.jebo.2008.09.003

Warnier, V., Weppe, X., \& Lecocq, X. (2013). Extending resource-based theory: Considering strategic, ordinary and junk resources. Management Decision, 51(7), 1359- 1379. https://doi.org/10.1108/MD-05-2012-0392

Webster, J., \& Watson, R. T. (2002). Analyzing the past to prepare for the future: writing a literature review. MIS Quarterly, 26(2), xiii-xxiii. https://doi.org/10.2307/4132319

Weitzman, M. L. (1998). Recombinant growth. The Quarterly Journal of Economics, 113(2), 331-360. https://doi.org/10.1162/003355398555595

Wenzel, M. (2015). Path dependence and the stabilization of strategic premises: How the funeral industry buries itself. Business Research, 8(2), 265-299. https://doi.org/10.1007/s40685-015-0021-4 
West III, G. P, \& DeCastro, J. (2002). The Achilles heel of firm strategy: Resource weaknesses and distinctive inadequacies. Journal of Management Studies, 38(3), 417442. https://doi.org/10.1111/1467-6486.00243

Whetten, D. A. (1989). What constitutes a theoretical contribution? Academy of Management Review, 4(4), 490-495. https://doi.org/10.2307/258554

Whittemore, R., \& Knafl, K. (2005). The integrative review: Updated methodology. Journal of Advanced Nursing, 52(5), 546-553. https://doi.org/10.1111/j.13652648.2005.03621.x

Williamson, O. E. (1979). Transaction cost economics: The governance of contractual relations. Journal of Law and Economics, 22(2), 233-261.

Williamson, O. E. (1981). The economics of organization: The transaction cost approach. American Journal of Sociology, 87(3), 548-577. https://doi.org/10.1086/227496

Williamson, O. E. (1983). Credible commitments: Using hostages to support exchange. American Economic Review, 73(4), 519-540

Youn, H., Strumsky, D., Bettencourt, L. M. A., \& Lobo, J. (2015). Invention as a combinatorial process: evidence from US patents. Journal of the Royal Society Interface, 12(106), 1-8. https://doi.org/10.1098/rsif.2015.0272

Zeppini, P., \& Van den Bergh, J. C. J. M. (2013). Optimal diversity in investments with recombinant innovation. Structural Change and Economic Dynamics, 24(1), 141-156. https://doi.org/10.1016/j.strueco.2012.09.002 